\title{
La frontera del Alentejo durante la Guerra de Restauración (1640-
} 1668)

\section{The Border of Alentejo During the Portuguese Restoration War $(1640-1668)$}

\author{
ANA TERESA GRAÇA DE SOUSA \\ Becaria HERITAS, CIDEHUS, Universidad de Évora \\ aana_sousa@hotmail.com
}

Resumen: La Guerra de Restauración (1640-1668) impuso la necesidad de proteger la frontera alentejana, recurriendo para ello a la reforma de las antiguas defensas castrenses y al desarrollo de nuevos proyectos de fortificación. En este contexto, sobresale el hecho de que algunos ingenieros militares, que hasta entonces habían estado trabajando en la adaptación de las fortificaciones del Alentejo, acabarán sirviendo al enemigo castellano, lo que obligó a la modificación sus proyectos. En el presente estudio enfocaré también las cuestiones de movilidad entre portugueses y castellanos, aportando ejemplos pertinentemente documentados. Se asiste a cruces fronterizos y asaltos para controlar la correspondencia entre uno y otro reino. Este control era sumamente valioso porque permitía averiguar no solo la situación en la que se encontraba el enemigo, sino que también daba acceso a saber su posición estratégica, pudiendo calibrar la distancia a la que se encontraba de la frontera y posibilitando una buena organización y el conocimiento del número de hombres y armas que tendrían. Analizaré todo lo dicho cotejando documentos que se encuentran en el Archivo Nacional de la Torre do Tombo, en Lisboa, en la Biblioteca Pública de Évora y en el Archivo General de Simancas.

Palabras clave: Guerra de Restauración, frontera, Alentejo, fortificaciones, correspondencia.

Abstract: The need for the Portuguese Restoration War arose between 1640 and 1668 ,
becoming imperative the defence of the Alentejo border through the adaptation of old
military defences and the elaboration of new projects. Thus, it is noted that some military
engineers, who were working on the adaptation of Alentejo fortifications at the time,
began to serve the Castilian enemy, making their projects to be modified. The mobility
between Portuguese and Castilian people during this period are also highlighted, indicating
concrete examples. Border crossings and assaults are taking into account to control the
correspondence between both kingdoms. This control also allows us to analyse the
situation of the enemy, being possible to know their strategic position, if they would be

Recibido: 3 de abril de 2017; aceptado: 6 de septiembre de 2017; publicado: 27 de marzo de 2018.

Revista Historia Autónoma, 12 (2018), pp. 99-119.

e-ISSN: 2254-8726; DOI: https://doi.org/10.15366/rha2018.12.005. 
close to the well-organized border places, as well as the number of men and the weapons they would have. These analyses will be made from original documentation existing in the National Archive of Torre do Tombo, in Lisbon, in the Public Library of Évora, and in the General Archive of Simancas.

Keywords: Portuguese Restoration War, Alentejo, Border, Fortification, Correspondence.

\section{Introducción}

La unión entre Portugal y Castilla bajo una misma corona a partir de 1580, dio lugar a un gran descontento ${ }^{1}$. Con la muerte del rey Sebastião de Portugal, Felipe II de Castilla surgió como sucesor legítimo al trono luso, siendo aclamado como rey de Portugal (conocido como Felipe I) en las Cortes de Tomar, en 1581.

Según Félix Labrador Arroyo, esta unión permitía la posesión de un importante imperio ultramarino, con índole militar y económica, que contribuía a la consolidación política de la monarquía hispánica².

Una de las primeras medidas que tomó fue ofrecer apoyo financiero a las clases más altas — “la fidalguía, el alto clero y miembros de la administración" — ${ }^{3}$, asegurando su autonomía administrativa bajo el principio de la unidad soberana, con una administración independiente, gestionada por portugueses. Además, se había comprometido a abrir las fronteras entre los dos países y a garantizar los fondos de solvencia para los problemas estructurales del reino.

Tras la muerte de Felipe I, en 1598, le sucedió en el trono su hijo, Felipe II de Portugal. Este rey optó por el modelo de nombrar validos como fórmula gubernamental. Así, entre 1598 y 1618, nombró al duque de Lerma, y entre 1618 y 1621, al duque de Uceda. Durante su reinado reforzó el poder centralizado en Madrid, reduciéndose de este modo la autonomía portuguesa ${ }^{4}$. El aumento de los impuestos en 1611 condujo al empobrecimiento de la población lusa.

A partir de 1620-1621, después de la muerte de Felipe II, la situación socio-económica y política empeora. El reinado de Felipe III de Portugal estuvo marcado por la administración

\footnotetext{
${ }^{1}$ Valladares, Rafael, "Sobre Reyes de Invierno. El Diciembre Portugués y los Cuarenta Fidalgos (o algunos menos, con otros más)", en Pedralbes, 15 (1995), p. 107.

${ }^{2}$ Labrador Arroyo, Félix, "Felipe II y los procuradores de Tomar (1581). La integración de las elites portuguesas a través de la Casa Real", en Bravo Lozano, Jesús (ed.), Espacios de poder: Cortes, ciudades y villas (s-XVI-XVIII). Vol 1, Madrid, Universidad Autónoma de Madrid, 2002, p. 172.

${ }^{3}$ Valladares, Rafael, "Sobre Reyes de Invierno..." op. cit., p. 109.

${ }^{4}$ Gama, Maria Luísa, O Conselho de Estado no Portugal Restaurado. Teorização, Orgânica e Exercício do Poder Político na Corte Brigantina (1640-1706), tesis de máster, Universidade de Lisboa, 2011, pp. 72-73.
} 
del conde-duque de Olivares. A pesar de sus reformas, no mejoró la imagen de Castilla ${ }^{5}$. La mayoría de las críticas durante la década de 1630 tendrían como objetivo reclamar el regreso a las formas tradicionales de gobierno del reino de Portugal y de la monarquía católica ${ }^{6}$. Las sucesivas guerras que Madrid mantuvo abiertas en Europa dieron lugar a una subida de impuestos desorbitada a la que se sumaba la movilización de los jóvenes portugueses para ir al frente, la disminución de la autonomía y la falta de protección en las colonias. El malestar de la población desembocó en el surgimiento de disturbios, en Oporto y Lisboa en 1629 y en Évora en $1637^{7}$.

Con estas premisas, en 1640, aprovechando el movimiento de tropas y las atenciones puestas en la sublevación de Cataluña, algunos nobles y eruditos portugueses se rebelaron ${ }^{8}$. Esta revuelta culminó con la restauración de la independencia de Portugal concretizada en la proclamación del duque de Bragança, que reinaría como João IV. Según Mafalda Soares da Cunha, esta revuelta cogió por sorpresa no solo a los representantes políticos de Felipe IV en Portugal, sino también a la propia monarquía castellana ${ }^{9}$. Aunque algunos portugueses volvieron a su país, la mayoría permaneció en Castilla. De esta forma se controlaron las fronteras para impedir que estos entregasen al nuevo gobierno informaciones, armas o dinero ${ }^{10}$.

En enero de 1641 João IV fue reconocido como rey en las cortes de Lisboa. La primera preocupación del nuevo monarca fue la consolidación del poder que había alcanzado. En el ámbito diplomático, envió embajadores a varias capitales europeas para tratar de obtener el aval de otros monarcas. A su vez, dio énfasis a los asuntos militares, pues se esperaban ataques por parte de los castellanos, dando luz verde al envío de todo el apoyo logístico que las fuerzas de Portugal precisaran para la guerra. Se abrieron fábricas de pólvora, salitre, armas, municiones y arsenales; se reforzó también la creación de un ejército permanente y organismos auxiliares como el Consejo de Guerra y la Junta de Frontera, cuya razón de ser era inspeccionar y tratar los temas relacionados con las fortificaciones y el estado de guerra. De esta manera, tanto este Consejo como la Junta, actuaron conforme a una nueva dimensión política, no solo administrativa, sino también con características militares. Aparte de la estrategia de los asuntos de naturaleza militar, en el Consejo se debatía además acerca de la gestión de los fondos recogidos para la guerra y sobre el dinero para el pago de los salarios de los soldados ${ }^{11}$. Así mismo, se crearon seis provincias militares - Entre Douro y Minho, Tras-os-Montes, Beira,

\footnotetext{
${ }^{5}$ Ibídem, pp. 75-76.

${ }^{6}$ Freire Costa, Leonor y Mafalda Soares da Cunha, D. João IV, Lisboa, Círculo de Leitores, 2006, pp. 38-39.

${ }^{7}$ Bouza Álvarez, Fernando, "Primero de diciembre de 1640: una revolución desprevenida", en Manuscrits, 9 (1991), p. 211. «http://www.raco.cat/index.php/Manuscrits/article/view/23186/92432» [consultado el 12 de enero de 2017]; Valladares, Rafael, "Sobre Reyes de Invierno..." op. cit., p. 113.

${ }^{8}$ Oliveira, António de, Movimentos Sociais e Poder em Portugal no Século XVII, Coimbra, Instituto de História Económica e Social da Faculdade de Letras da Universidade de Coimbra, 2002, p. 11.

${ }^{9}$ Soares da Cunha, Mafalda, "O significado da «Restauração»", en de Matos, Artur Teodoro (coord.), Memória de Portugal. O milénio português, Lisboa, Circulo de Leitores, 2001, p. 355.

${ }^{10}$ Rodríguez Hernández, Antonio José, "Nación, fidelidad y frontera durante la Guerra de Restauración de Portugal (1640-1668)", en Iñesta Mena, Félix y Francisco Mateos Ascacíbar (coord.), España, Nación y Constitución y otros estudios sobre Extremadura, Llerena, Sociedad Extremeña de Historia, 2011, p. 66.

${ }^{11}$ Gama, Maria Luísa, O Conselho de Estado... op. cit., p. 80.
} 
Estremadura, Alentejo y Algarve_— ${ }^{12}$, siendo la provincia de Alentejo la más vasta y vulnerable por sus características topográficas, consistiendo en:

"huma continuada extenção de terreno, situado da parte d'além do Rio Guadiana, cuja legitima posse não pode ser contestada de modo algum se não pela injustiça, pela violencia e pela muita força. Ella na maior parte da sua extenção hé plana, e por esta cauza tem sido particularmente escolhida em quazi todas as Guerras para as reprezentações militares"13.

De la mano de João IV, se crearon nuevos mandos militares, adaptados a la situación de guerra, como el de teniente general de artillería, que respondía a la Junta de los Tres Estados, a la Junta del Comercio y al Consejo Ultramarino, así como los gobernadores provinciales de armas de la provincia del Alentejo. Todo este aparato se utilizaba para apoyar al Ejército portugués. De esta manera, se prepararon ejércitos y se dispusieron medios para financiar el esfuerzo inherente a la guerra, con una importante cobertura logística para las batallas en la frontera ${ }^{14}$.

La necesidad de defenderse llevó a la adaptación de las fortificaciones del Alentejo al sistema abaluartado. Para tal efecto, se proyectó la concentración de plazas fuertes entre Moura y Castelo de Vide, y se otorgó prioridad al refuerzo defensivo de ciudades del interior, como Évora y Beja. Con idéntico propósito surgió una tipología constructiva basada en diversas intervenciones que iban desde el recinto de Elvas hasta la aglutinación de puntos defensivos más pequeños, como baluartes aislados, fuertes y fortines, variando de acuerdo a la prioridad de ataque del enemigo.

En calidad de Generalísimo de Armas del Reino, el príncipe Teodosio defendió la fortificación de Évora, requiriendo la ayuda de la población, tanto física como monetaria. Con las muertes del príncipe, el 15 de mayo de 1653, y del rey João IV, el 6 de noviembre de 1656, se detuvieron las obras. La reina viuda, Luísa de Gusmão, se vio obligada a nombrar como Generalísimo de Armas del Reino a su otro hijo, el futuro rey Afonso VI. En este periodo estalló el primer ataque de los castellanos, bajo el mando del duque de San Germán, y cuyo escenario fue la plaza fuerte de Olivenza, en abril de $1657^{15}$. En esta tesitura, la guerra tuvo que hacerse de forma defensiva, según consejo de Francesco Tuttavilla, encargado de dirigir las operaciones militares de Extremadura ${ }^{16}$.

\footnotetext{
12 "Descrição de Portugal que tem por principal assunto falar de suas praças", Biblioteca Pública de Évora [en adelante, BPE], Fundo Manizola, Cod. 509-1, f. 6.

${ }^{13}$ Ibídem, ff. 7-8.

${ }^{14}$ Cardim, Pedro, “A diplomacia da Restauração", en de Matos, Artur Teodoro (coord.), Memória de Portugal... op. cit., p. 356.

${ }^{15}$ Sousa Lobo, Francisco, "Batalhas da Restauração", en Revista Monumentos, 7 (1997), p. 84.

${ }^{16}$ Revilla Canora, Javier, "Un noble napolitano en la Guerra de Portugal: Francisco Tuttavilla, duque de San Germán, general del Ejército de Extremadura", en Labrador Arroyo, Félix (coord.), II Encuentro de Jóvenes investigadores en Historia Moderna. Líneas recientes de Investigación en Historia Moderna, Madrid, Universidad Rey Juan Carlos-Cinca, 2015, p. 393.
} 
Con todo, el primer gran ataque de los castellanos se atribuye a la batalla de Ameixial, el 8 de junio de 1663. Según Lorraine White, el ejército portugués que había estado bloqueando la ruta hacia Juromenha salió al encuentro del enemigo ${ }^{17}$. La campaña fue considerada por el Consejo de Guerra de la Monarquía católica como el momento ideal para poner fin a la resistencia lusa ${ }^{18}$, a pesar de lo cual, los portugueses vencieron.

Un nuevo enfrentamiento entre las dos fuerzas tuvo lugar en Montes Claros, contra Luís de Benavides, "carregado com a fama de dezassete batalhas em que saíra vencedor"19. Este fue derrotado por los portugueses, quedando al descubierto la debilidad del poder de Castilla.

A la muerte de Felipe IV, acaecida en septiembre de 1665, sube al trono su hijo, el rey Carlos II. Al ser menor de edad, asumió la regencia su madre, quien procuró hacer las paces con Portugal debido a la debilidad del gobierno ${ }^{20}$. Se asignó una comisión, aprobada el 5 de enero de 1668, y enviada con el objetivo de negociar con Don Gaspar de Haro y Guzmán, siendo hechas las paces con el príncipe Pedro, quien reinaba en nombre de su hermano Alfonso VI, que había sido depuesto. La paz se firmó el 10 de marzo de ese mismo año.

Observando la documentación del periodo en causa, es interesante ver cómo se procedió al paso de la frontera del Alentejo; de qué manera portugueses y castellanos cruzaron de reino a reino; quién tenía más posibilidades de atravesar la frontera; si sería fácil o no hacerlo...

Reflexionaremos sobre estas cuestiones a partir de correspondencia de la época recogida en Portugal y España.

\section{La defensa de la frontera del Alentejo: las fortificaciones}

Durante el período de la Guerra de Restauración, entre 1640-1668, urgió fortalecer las defensas del Alentejo, por ser la provincia más vulnerable. Según María José Rodríguez Trejo, se "convertían a las fronteras y a los fronterizos en los principales escenarios y protagonistas del conflicto"21 [fig. 1].

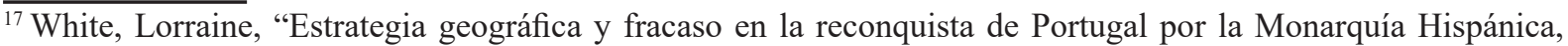
1640-1668”, en Studia histórica. Historia Moderna, 25 (2005), p. 60.

${ }^{18}$ Monteiro, Nuno Gonçalo, "A Guerra da Restauração", en de Matos, Artur Teodoro (coord.), Memória de Portugal... op. cit., p. 366.

${ }^{19}$ Espanca, Túlio, "Fortificações e Alcaidarias de Évora", en A Cidade de Évora, 9-10 (1945), p. 191.

${ }^{20}$ Rodríguez Rebollo, María Patricia, "El Consejo de Estado y la Guerra de Portugal (1660-1668)", en Investigaciones Históricas: época moderna y contemporánea, 26 (2006), p. 134.

${ }^{21}$ Rodríguez Trejo, María José, "La Guerra de Restauración Portuguesa y la frontera: una nueva línea de investigación”, en Labrador Arroyo, Félix (coord.), II Encuentro de Jóvenes... op. cit., p. 559.
} 
Figura 1: Las Fronteras de España y de Portugal, Nicolás de Fer, 1742 [detalle].

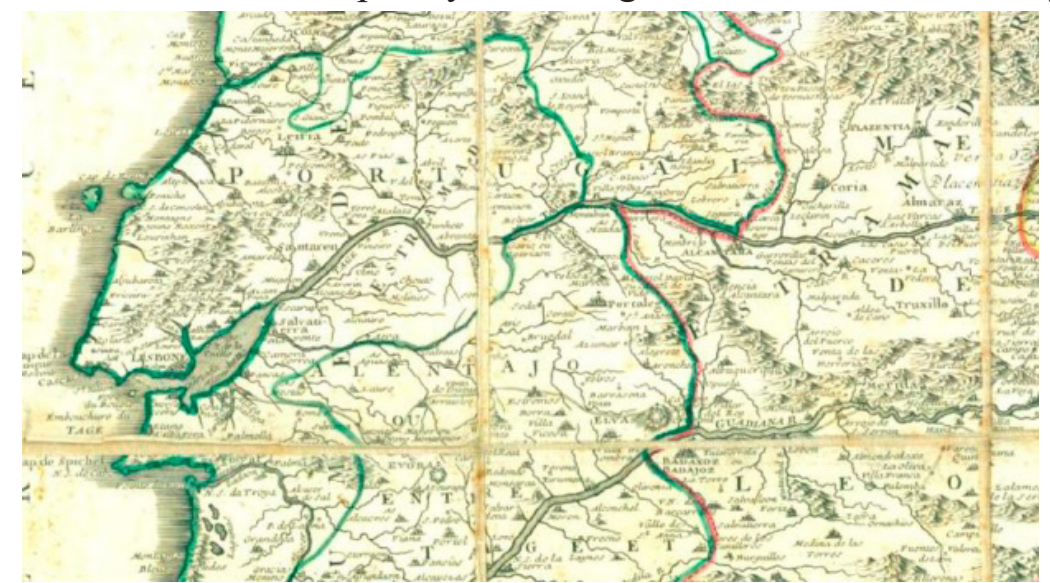

Fuente: Gallica. «http://gallica.bnf.fr/ark:/12148/btv1b5966872d» [consultado el 22 de abril de 2015].

Sin embargo, la propia definición de frontera es compleja. Durante el período filipino hubo el incentivo a la permeabilidad de la frontera, encontrándose esta casi estabilizada. Por el contrario, en la época de la Guerra de Restauración nosotros nos encontramos con el desempeño de la frontera como línea separadora. En este contexto, la presión de sus acontecimientos llevó a la urgencia de un sistema defensivo eficazmente delineado, en el cual se incluían las fortificaciones y los preparativos militares de campaña ${ }^{22}$.

Por eso, se trabajó principalmente en las fortificaciones de Évora, Campo Maior, Juromenha, Ouguela, Elvas, Estremoz, Monsaraz, Olivenza, Beja, Moura y Serpa [fig. 2].

Figura 2: Carta de la frontera entre el Alentejo y la Extremadura Española, João Teixeira Albernaz y Lucas Vosterman, 1644 (detalle).

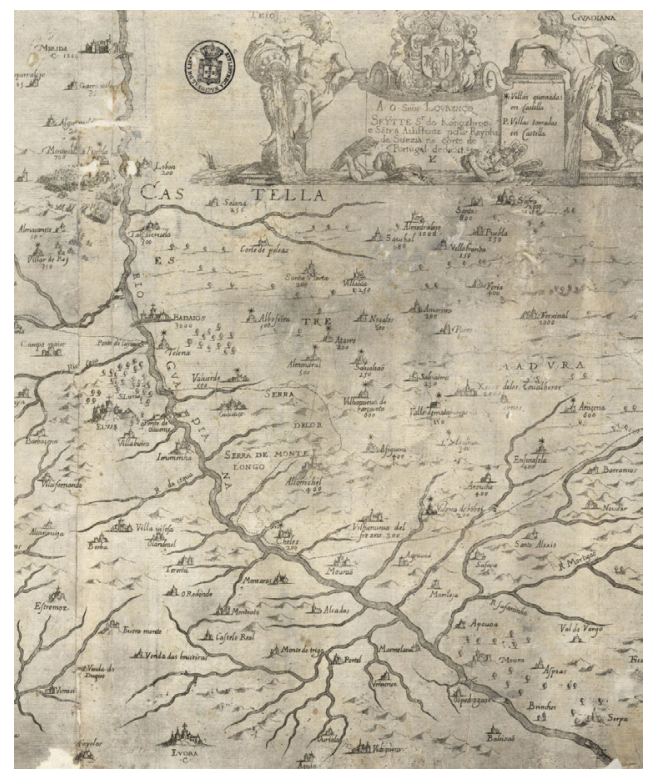

Fuente: BNP. «http://purl.pt/918/3/» [consultado el 4 de marzo de 2017].

${ }^{22}$ Da Conceição, Margarida Tavares, "Configurando a praça de guerra: o espaço urbano no sistema defensivo da fronteira portuguesa", en Rossa, Walter et al. (coords), Actas do Universo Urbanístico Português: 1415-1822, Lisboa, Comisión Nacional para la Conmemoración de los Descubrimientos Portugueses, 2001, pp. 825-839. 
Según Fernando Cobos-Guerra y João Campos, podemos ver la fortificación de la frontera portuguesa como "um sistema próprio" ${ }^{23}$, con coherencia tecnológica y tipológica, en respuesta a los principios de fortificación de mediados del siglo XVII, cuando se había recurrido al trabajo de los ingenieros militares extranjeros para llevar a cabo proyectos de adaptación de las construcciones castrenses y para el desarrollo de nuevos sistemas fortificados. Se destacaron, por encima de todos los trabajos de los ingenieros militares franceses João Gilot, Nicolau de Langres y Pierre de Saint-Colombe [fig. 3]. También sobresalió la intervención de Paschácio de Cosmander, partidario del método de fortificación holandés.

Figura 3: Ingeniero militar y dos asistentes dibujando una fortificación, c. 1661.

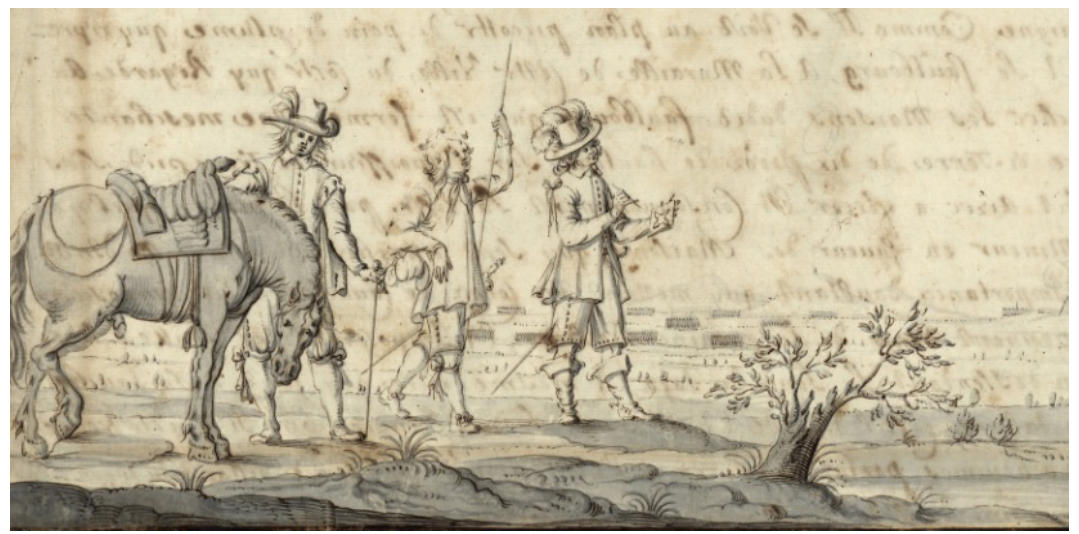

Fuente: Desenhos e plantas de todas as praças do Reyno de Portugal Pello Tenente General Nicolao de Langres Francez que serviu na guerra da Acclamação, BNP, f. 2. «http://purl.pt/15387/5/index.html» [consultado el 27 de junio de 2014].

A este respecto se menciona una carta del 2 de junio de 1646, firmada por Joane Mendes de Vasconcelos, Gobernador de Armas de la provincia del Alentejo, y que iba dirigida al monarca João IV. En ella indicó que los párrocos de la catedral de Évora habían manifestado el deseo que tenían de financiar la construcción de una fortificación en los puertos del Guadiana que impidiera la entrada del enemigo castellano. Pidieron el envío del ingeniero militar Gilot para reconocer el terreno y elaborar un proyecto de fortificación. En lugar de Gilot, el gobernador envió a Nicolau de Langres, por estar en aquel tiempo más libre y más cerca del lugar ${ }^{24}$.

Según otra carta del mismo gobernador, fechada el 4 de septiembre de ese año, la localidad de Campo Maior tampoco tenía fortificación para defenderse, poseyendo solo una línea fortificada con obras exteriores para detener el avance del enemigo. Solo con esta línea fortificada no podría resistir muchos días al ataque del adversario, pudiendo sufrir daños antes de que los portugueses llegaran para socorrerles ${ }^{25}$.

\footnotetext{
${ }^{23}$ Cobos-Guerra, Fernando y João Campos, Almeida/Ciudad Rodrigo. La Fortificación de la Raya Central, Salamanca, Consorcio Transfronterizo de Ciudades Amuralladas, 2013, p. 20.

${ }^{24}$ Archivo Nacional Torre do Tombo [en adelante, ANTT], Mans. Liv. 610, ff. 13v-14v.

${ }^{25}$ ANTT, Mans. Liv. 610, ff. 162v-163.
} 
Además, el lugar necesitaba de una ciudadela: "necessita principalmente de huma sitalada" ${ }^{26}$. Cosmander y Langres diseñaron sendos proyectos; el elegido tendría que ser aquel que menos casas sacrificase ${ }^{27}$.

Posteriormente, el 21 de enero de 1648, el Maestro Mayor de Campo del Alentejo, Afonso Furtado de Mendonça, relató que el trabajo de esta fortificación se había detenido por falta de dinero. Afirmó haber pedido un préstamo de seiscientos mil reis para que se pudiera acabar el baluarte de São Sebastião. Ya se habían construido parapetos a prueba de cañón, por lo que quedaría aquella posición segura; y ya se había trabajado "com grande cuidado" en los baluartes cercanos a la ciudadela. Sin embargo, al ser este trabajo muy laborioso y de elevado coste económico: "he de pedra e cal, e a não há nesta vila", necesitaban que el monarca enviase más dinero para continuar las obras ${ }^{28}$. El proyecto de fortificación seguido fue obra de Nicolau de Langres [fig. 4].

Figura 4: Proyecto de la fortificación de Campo Maior, c. 1661.

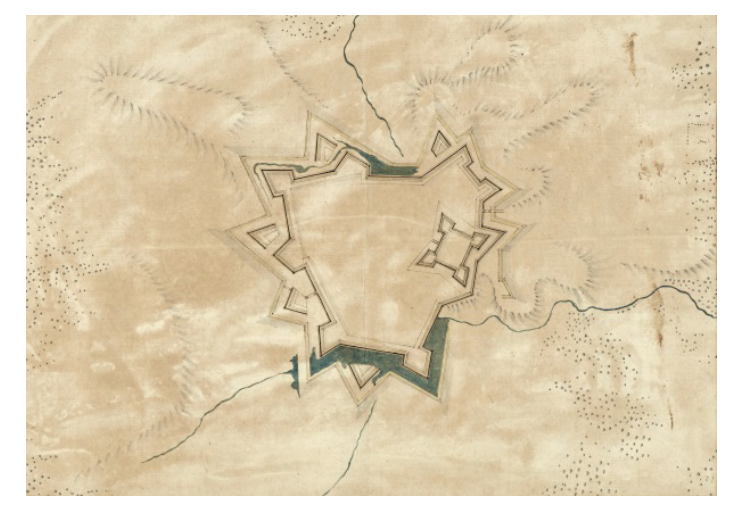

Fuente: Desenhos e plantas... op. cit., f. 7.

El 26 de septiembre de 1646, el conde de Alegrete informó a João IV sobre la eficacia del fuerte de Terena frente a la amenaza castellana. Se habían sacudido con artillería y morteros la estacada que el enemigo tenía en el exterior de la fortaleza de San Juan de Liganes. El combate se alargó veinticuatro horas:

"Hoje apertamos com as baterias de Artilharia, e Morteyros, e com hum aproche a estacada que o Inimigo tinha por fora do seu Forte São João de Liganes e foi tal a rezolução que a esta hora chego a este Quartel de fazer os partidos ao Sargento Mór que o governava, e a 200 soldados velhos, que ham de passar a esse Reino sem armas emquanto durar o andarem as Armas

\footnotetext{
${ }^{26}$ Fuerte de cuatro o cinco ángulos que se fabricaba a lo largo de la plaza, "ou dentro para as dominar, enfrear, e bater sendo necessário". Serrão Pimentel, Luís, Methodo Lusitânico de Desenhar as fortificações das Praças Regulares e Irregulares fortes de campanha, e outras obras pertencentes à Arquitectura Militar, Lisboa, Oficina de Antonio Craesbeeck de Mello, 1680, p. 15.

${ }^{27}$ ANTT, Mans. Liv. 160, ff. 163.

${ }^{28}$ ANTT, Cons. Guerra, Mç. 8, doc. 55, sf.
} 
de V. M. em Campanha este anno, ham de ser retidos, e despois enviados para Castella sem união, nem formatura, mas soltos por honde se lhes Ordenar, entregou-se este Forte havendo pelejado estas 24 horas, e defendendo-se"29.

Conviene destacar una carta del 2 de diciembre de ese año remitida por Joane Mendes de Vasconcelos al monarca, en la que afirmó que el pueblo de Ouguela corría el riesgo de quedar expuesto de no levantar una fortificación para defenderlo, pudiendo el enemigo ganar la plaza sin dificultad. Esta situación era preocupante, ya que Ouguela constituía la puerta de entrada a Campo Maior, Arronches, y zonas lindantes. Debería hacerse algo para su defensa y para animar su guarnición. Señaló que sería necesario algún dinero para la obra, en la que se tendría que empezar a trabajar en primavera, y de esta manera ya podrían resistir al enemigo "que se nam hade descuidar de vir sobre ella, tendo occazião, porque a dezeja"30.

En relación con la preocupación por Juromenha, plaza más cercana a la frontera con Castilla, destaco una carta del 23 de septiembre de 1646, donde el conde de Alegrete informó de que se había establecido la planta de su fortificación, siendo el de Nicolau de Langres el proyecto más a propósito para la adaptación al terreno que el que había sido diseñado por Cosmander. Indignado, Cosmander criticó el proyecto de Langres, alegando la dificultad que entrañaba ponerlo en práctica $^{31}$.

El conde de Alegrete dice además que cuando comenzó a organizar los tercios, fue advertido de que Cosmander había ido a Lisboa sin su conocimiento y sin licencia para desplazarse, lo que era "perjudicial consequencia" 32 . Tal actitud nos muestra que Cosmander estaba indignado porque habían preferido el proyecto de Langres al suyo pudiendo, eventualmente, aliarse a los castellanos.

Posteriormente, el 5 de diciembre de 1646, Joane Mendes de Vasconcelos subrayó de nuevo la importancia de esta fortificación, siendo el paso principal del enemigo para los enclaves de Olivenza, Vila Viçosa y Borba. Sería indispensable que se efectuasen mejoras con brevedad en su fortificación, "porque nos nam arrependemos algum dia de o não haver feito". Llegó a indicar que por la urgencia de la situación, se habían proyectado tres planos para dicha fortificación. Uno de los planos era de la autoría del ingeniero militar Pascoel. Su plano no resultó práctico, por situarlo muy cerca del castillo y por obligar a que se desmantelara todo el lugar, dejando al mismo sin capacidad para construir casas entre el castillo y la nueva fortificación: "huma fez Paschoel arrimando-se muito ao Castello, derrubando todo o lugar sem deixar capacidade entre o Castello e a Forteficação para se fazerem cazas, e o que faz vem a ter pouco mais que franquear a obra do mesmo Castello". Otro era de la autoría de Cosmander, que propuso el derribo de todos los elementos existentes, haciéndose una construcción completamente nueva:

\footnotetext{
${ }^{29}$ ANTT, Mans. Liv. 610, ff. 112-113v.

${ }^{30}$ ANTT, Mans. Liv. 610, ff. 163-163v.

${ }^{31}$ ANTT, Mans. Liv. 610, ff. 122-123.

${ }^{32}$ Ibídem.
} 
"outra Planta hé de Cosmander, que sem fazer cazo do luguar, vay ganhar duas emminências distantes delle, derrubando tudo quanto há, e deyxando outras muy prejudiciaes para a sua defensa". Esto no era admisible, ya que perjudicaría la defensa de la plaza, que quedaría demasiado frágil durante el transcurso de las obras. Por último, tenemos el proyecto de Langres, que se antojaba el mejor, ya que no sugirió ningún sacrificio; proponía cerrar el castillo con dos baluartes completos: "a Terceyra hé de Langres, que sem derrubar o luguar ganha as emminencias que lhe podem fazer danno, ferrando-a com o Castello que fica segunda retirada, hé de dous Baluartes inteiros, dos menores que se faz em todo o Mundo"33.

Según el propio gobernador, al considerarse las tres plantas, la de Langres era la más viable; no solo tenía un coste más bajo que el proyecto de Cosmander, sino que además evitaba la intención de este último de sacrificar las construcciones preexistentes, lo que frustraría una de las principales preocupaciones a la hora de construir una fortificación, que era albergar a sus residentes, quienes tendrían que ausentarse durante las obras. Sin la seguridad adecuada, los residentes no volverían, siendo que "não hé aquelle povo de tam pouca importancia que se haja de perder por quatro ou seis mil cruzados, que isto mesmo ham de custar as cazas em qualquer parte que se houverem de fazer"34.

Con carácter de urgencia, era imprescindible que se aclarara si tendría que trabajarse en la fortificación con los medios de los propios ingenieros militares o por cuenta del monarca, en cuyo caso se pedía que remitiera el dinero tan pronto como fuera posible "para se começar com o calôr que convem" 35 .

El mismo día, Joane Mendes de Vasconcelos nos dio cuenta de las plantas de las fortificaciones de Elvas, Olivenza, Campo Maior y Ouguela. Señaló que era asunto de fuerza mayor la construcción de la fortaleza de Juromenha, por ser "a maior consequencia que hoje há para se haver de forteficar com toda a presteza, e diligencia que convem, sem que se suspenda mais annos". No estaría satisfecho hasta verla fortificada "pelo perigo que considéro a todos os lugares de huma e outra parte de Guadiana se o Inimigo occupasse este Posto"36.

Más tarde, el 22 de abril de 1648, el Gobernador de Armas del Alentejo, Martim Afonso de Melo, también conocido como Segundo conde de São Lourenço, advirtió a João IV de que con la ausencia de Cosmander en aquella provincia, a quien se le había encargado la obra, se había dejado de trabajar en la fortificación de Juromenha. Ha establecido que "em huma obra tam necessaria como esta e não haver pessôa particular a quem se encarregue nunqua háde acabar" ${ }^{37}$. Según él, si no se ocupasen de esta fortificación con urgencia en el presente, incluso habiendo dinero para continuarla posteriormente, cuando el enemigo tratase de ganarla, esta no tendría ya ninguna utilidad.

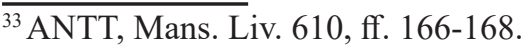

${ }^{34}$ Ibidem, f. $167 \mathrm{v}$.

${ }^{35}$ Ibidem.

${ }^{36}$ ANTT, Mans. Liv. 610, f. 170v.

${ }^{37}$ ANTT, Mans. Liv. 610, ff. 387- 388v.
} 
Poco después, el 19 de junio de ese mismo año, el mismo gobernador informó de un ataque del enemigo contra Juromenha, en el que murió Cosmander, ya al servicio de los castellanos. Narró que, al amanecer, habían atacado la fortificación por cuatro flancos "arrimando escadas, e petardos, à muralha". Después de haber entrado trescientos castellanos dentro de la plaza, los portugueses acudieron a todos los frentes, siendo que de los trescientos murieron ciento cincuenta y cuatro "todos officiaes vivos, e reformados"; y otros treinta y cinco se encontraban heridos en el hospital, entre los cuales "trez cappitaens, dous de Infantaria, e hum de caballos". Indicó también que Cosmander fue uno de los primeros en morir: "Cosmander, se affirma, foi o primeyro que subio, e tambem foy dos primeyros que o pagárem com a vida"38.

El 11 de marzo de 1648, el mismo gobernador advirtió al monarca de la importancia y necesidad que existía de que se formasen personas en Portugal en materia de fortificación, "pelo grande trabalho que temos com os Estrangeyros". Además de por los problemas que causaban los ingenieros militares extranjeros también veían ventajoso formar a sus propios ingenieros porque los que venían de fuera eran muy avariciosos y según se llenaban los bolsillos se marchaban "pera as suas Terras como cada dia experimentamos"

El 15 de enero de 1650, el Gobernador de Armas del Alentejo, André de Albuquerque, escribió a João IV acerca de la orden que él había dado para que los rendimientos de los condados de Elvas, Évora y Beja se aplicasen en las obras de las fortificaciones del Alentejo: "por ser condição de seu contrato, assy se fez" ${ }^{\prime 4}$. De dicho rendimiento se entregaban cada año unos seis contos para dichas obras.

En otra carta suya, datada el 16 de febrero del mismo año, confirmó al monarca que el pueblo de Elvas había autoimpuesto el gravamen de dos reis por cada arrátel de carne y medio litro de vino para las fortificaciones. De hecho, en 1648, este impuesto había generado unos doce mil cruzados; en 1649 solo generó cuatro mil cruzados ${ }^{41}$, pero en ese año de 1650, había rendido entre catorce y quince mil cruzados.

El 10 de febrero de ese año, el mismo gobernador informó sobre la ruina en que se encontraba la fortificación de Olivenza, señalando que el mal tiempo había sido la causa de su destrucción. Esta fortificación se encontraba expuesta, sin gente suficiente para guarnecer todos sus baluartes, siendo que solo cuatro de ellos estaban ocupados, quedando por habitar otros nueve. Para evitar un mal mayor, André de Albuquerque envió al emplazamiento al capitán Diogo de Aguiar, con un fondo de "tres mil crusados para acodir ao reparo das ruinas". Pero con tan poco dinero, no se lograrían avances significativos en la obra. Por lo tanto:

\footnotetext{
${ }^{38}$ ANTT, Mans. Liv. 6100, ff. 435-437.

${ }^{39}$ ANTT, Mans. Liv. 610, ff. 356v-357v.

${ }^{40}$ ANTT, Cons. Guerra, Mç. 10, doc. 23, sf.

${ }^{41} \mathrm{La}$ reducción registrada en 1649 se debió a que el tesorero de las fortificaciones se había apropiado del dinero recaudado. Parte de ese rendimiento se destinó a trabajos en las fortificaciones, al apoyo de los expósitos y a la limpieza de la ciudad de Elvas. ANTT, Cons. Guerra, Mç. 10, doc. 49, sf.
} 
"Para se acrecentar a guarnição aquella praça não havia em todas aquellas fronteiras parte donde se possa tirar pella pouca gente que tem os terços [...] com que era força recorrer aos Auxiliares, sobre o que avia escrito ao Governador da comarca de Evora ao corregedor de Villa Viçosa, para que de huma, e outra parte se lhe enviassem quinhentos para os deixar em Elvas, $e$ enviar dos soldados pagos a Olivença, adonde tambem mandaria acrecentar a guarnição da cavalaria"42.

Destacar que después de la Guerra de Restauración, todavía se dejaban sentir los desacatos de los portugueses en la frontera con Castilla. Encontramos descrito este hecho en una carta de 22 de abril de 1670 enviada a la reina regente, Mariana de Austria. En esta misiva se mencionó también que las fortificaciones de la frontera castellana se encontraban en miserable estado de defensa y abandono, mientras que los portugueses ya habían reparado las suyas. Según la misma información, las construcciones militares portuguesas estaban ahora mejor preparadas que en tiempos de guerra. Además, los vecinos lusos habían asistido a sus puestos fronterizos con prontitud, habían reclutado tercios y su artillería estaba preparada. Según el marqués de Montalbán:

\footnotetext{
"Solo se puede añadir la ponderasion de que sean nuestros enemigos los que nos avisen de que estamos perdidos, y de que en tanto tiempo no se haya dado un passo en el reparo de las fronteras con que es preciso hacer planta de lo que se debe obrar y dar regla a los gobernadores de lo que han de hacer en qualquier acontecimiento" ${ }^{\prime 4}$.
}

\section{Cruzar la frontera entre Alentejo y Castilla: ejemplos concretos}

Durante la Guerra de Restauración, el trasiego de personas en la raya luso-castellana no fue fácil. Hubo un fuerte control en los sitios fronterizos, sobre todo en el Alentejo, por ser el terreno más amplio y más fácil de penetrar. Las traiciones entre los dos estados eran comunes. Incluso, algunos soldados portugueses estarían aún a favor de Castilla. Además, era común el saqueo y el pillaje con la subsecuente destrucción de los recursos ${ }^{44}$.

\footnotetext{
${ }^{42}$ ANTT, Cons. Guerra, Mç. 10, doc. 41, sf.

${ }^{43}$ Archivo General de Simancas [en adelante, AGS], Est. Leg: 2617, sf.

${ }^{44}$ García Blanco, Julián, "Las poblaciones del corregimiento de Badajoz durante la Guerra de Restauración de Portugal (1640-1668), en Lorenzana de la Puente Felipe y Francisco Mateos Ascacibar (coords.), Iberismo. Las Relaciones entre España y Portugal. Historia y Tiempo Actual, Llerena, Sociedad Extremeña de Historia, 2007, p. 158.
} 
En carta del 7 de febrero de 1641, dirigida a Felipe IV, un soldado castellano manifestó que por su honor daría la vida al servicio de este monarca. Señaló que junto a él, estaban "algunos caballeros Portugueses todos tan deseosos de morir por la obediencia de V. M. que solo eso tendrían por gloria sin querer más primero que quedar publica [sic.] al mundo su lealtad"45.

También tenemos el ejemplo del soldado Francisco de Castilho [sic.], castellano que se había pasado al bando de Portugal a través del Alentejo en 1646; así lo denuncia Joane Mendes de Vasconcelos en una carta del 10 de junio. Escribió que Castilho se había unido al enemigo hacía unos días para huir de la posible condena por haber asesinado a un hombre. Joane Mendes de Vasconcelos pidió al monarca que se investigase, escuchase y se sometiese a interrogatorio a Castilho, a fin de saber si tenía alguna relación con el teniente Miguel de Andrade, que se encontraba detenido en Elvas. Según él, estas personas fugitivas no eran fieles a los portugueses, y que por este motivo, también el teniente debería ser investigado en profundidad, por no haber servido en Flandes y decir que había empezado a apoyar al reino de Portugal por respeto a Joane Mendes de Vasconcelos, siendo que también había manifestado que era de nacionalidad portuguesa, nacido en Ponte de Lima ${ }^{46}$.

Además de los soldados, también entre los frailes había quien pensaba en cruzar la frontera para dirigirse a Portugal. A este respecto, el 19 de junio de 1646, Joane Mendes de Vasconcelos informa a João IV sobre que se había prohibido a los frailes castellanos cruzar la frontera, quedando a la espera de sus órdenes para actuar: "as primeiras ordens de V. M. bastão para que eu lhes dê inteiro comprimento" ${ }^{47}$.

Sobresalen también los casos de personas anónimas. En este sentido, destaca una carta datada el 4 de septiembre de 1646, en la cual el conde de Alegrete informó a João IV acerca del caso particular de João Soares Vivas, Gonçalo de Barros y João de Barros, que se creía que habrían pasado al reino de Castilla. Indicó que, transcurridos solo seis días desde su llegada a la plaza de Elvas, se dio cuenta de la ausencia de João Soares Vivas, Gonçalo de Barros y su hermano, João de Barros, siendo que tampoco se sabía nada del pedalero de tres de sus sirvientes ${ }^{48}$.

El Maestro de Campo General de la plaza de Elvas manifestó su deseo de ordenar que los oficiales fuesen a casa de aquellos individuos para hacer un inventario de los bienes que tenían e intentar encontrar pistas que delatasen su intención de abandonar Portugal. Ha señalado que

\footnotetext{
"Joam Soares ouvi que tinha joyas e cantidad de dinheyro, e nam se lhe achou mais que tres pipinhas de marfim de algalea, huma faca, huma colher, hum garfo, e roupa, e a hum moço seu quinze, ou deseseis mil réis, que disse lhe dera antes que fosse para se curar, que estava doente" ${ }^{94}$.
}

\footnotetext{
$\overline{{ }^{45} \text { AGS, Est. Leg: }}$ 2614, sf.

${ }^{46}$ ANTT, Mans. Liv. 610, ff. 25-25v.

${ }^{47}$ ANTT, Mans. Liv. 610, ff. 65v-66.

${ }^{48}$ ANTT, Mans. Liv. 610, ff. 97-98.

${ }^{49}$ Ibídem, f. 97v.
} 
Por los detalles citados sabemos que João Soares Vivas tenía joyas pero que no se habían encontrado en su casa; el Maestro de Campo creía que muy probablemente estos hombres cruzaron la frontera durante la noche. Siendo este asunto de urgencia, había determinado enviar la información, acompañada de unos papeles donde se mostraba lo que Soares Vivas tendría que cobrar: "me pareceo despachar logo este pela porta a toda a diligencia, enviar com ella huns róis de que se mostra o que Joam Soares tinha para cobrar" 50.

Dos días después, el 6 de septiembre, el conde de Alegrete informó de que había tenido noticia del mencionado João Soares Vivas a través de un teniente francés que había pasado por la plaza de Elvas. Este teniente confirmó que tanto él, como Gonçalo de Barros y su hermano habían atravesado la frontera para dirigirse a Castilla. Concluyó indicando que el auditor general tomaría nota de la fuga de estos hombres: "e della se hade achar muita clareza"51.

Dos meses más tarde, el 3 de noviembre de 1646, el conde de Alegrete informó de que el maestro de campo de Olivenza, Antonio Ortis de Mendonça, había escrito una carta contando que por aquel lugar había pasado un soldado a caballo, de nacionalidad holandesa, que había estado al servicio del enemigo castellano. El conde de Alegrete envió esta advertencia a Vila Viçosa, Alandroal, Telena, Monsaraz, Mourão, Moura, Serpa y Mértola. También organizó el envío de dos rondas y de una tropa, con la intención de hacer un reconocimiento de los movimientos tácticos que estaría practicando el enemigo, ya que ese soldado holandés que iba a caballo bien pudiera ser un espía. Sin embargo, los maestros de campo de los lugares citados alertaron de que el enemigo se estaba refugiando en Badajoz con seis batallones de infantería, veintiséis tropas de caballos y una gran cantidad de coches con víveres y municiones ${ }^{52}$.

En 1647, a través de una carta datada el 23 de enero, Joane Mendes de Vasconcelos informó de que desde hacía aproximadamente un mes habían huido hacia Castilla entre diez y doce soldados de las compañías del comisario general Alexandre Vanhaterm y del capitán Gerardo Vanigen. También tenía noticias de que estos soldados, una vez llegaban a Badajoz, vendían sus caballos para conseguir pasaportes que les permitieran entrar en Cataluña. La mayor preocupación era que, en ese momento, debido a la muerte del comisario Alexandre Vanhaterm, estas fugas pudieran acentuarse ${ }^{53}$.

Más tarde, el 10 de enero de 1649, Martim Afonso de Melo siguió quejándose del mismo problema. Argumentó que en los últimos días había sido cada vez más frecuente la fuga de soldados portugueses hacia Castilla. Según él, sospechaba que estas fugas podían estar relacionadas con que se había corrido la voz de que en Lisboa se estaban reclutando soldados que se embarcasen para ir al frente en las colonias; este hecho provocó que los hombres más jóvenes vieran como alternativa a la guerra ultramarina la huida a Castilla. De confirmarse esto, era muy perjudicial para el servicio de João IV que se reclutara a soldados veteranos, pudiendo

\footnotetext{
${ }^{50}$ Ibídem, f. 98.

${ }^{51}$ ANTT, Mans. Liv. 160, ff. 99v-102v.

${ }^{52}$ ANTT, Mans. Liv. 610, ff. 137-139v.

${ }^{53}$ ANTT, Mans. Liv. 610, ff. 192v-193.
} 
optar por tener hombres más jóvenes a su servicio. Pidió al monarca que se investigase muy bien a estos soldados que se alistaban al servicio de las plazas de Castilla, y que si se confirmasen sus sospechas esta acción tendría que castigarse. De otro modo, de los pocos soldados con los que contaba Portugal no quedaría ninguno, siendo muy perjudicial porque había mucho trabajo por hacer en la frontera alentejana y era urgente acometerlo para poder hacer frente al enemigo ${ }^{54}$.

El 7 de junio de este mismo año, el mismo gobernador informó a João IV de que un tal Jorge Manuel había huido a Castilla. Este individuo no tendría orden real para volver a Portugal por la frontera del Alentejo. Aunque no había conseguido informar al maestro de campo general de Elvas sobre lo sucedido, dice que había alertado a los demás lugares de la frontera y a las personas que los gobernaban, para que no permitieran que este hombre entrara en Portugal ${ }^{55}$.

Posteriormente, el 17 de agosto de dicho año, se ha puesto en conocimiento que un individuo llamado Luis Queixada había cruzado la raya a través de Badajoz, y que después se había establecido en Elvas. Al parecer, este individuo pasaría la frontera tras tener diferencias con un sirviente de un pariente suyo, que era capitán de caballos, de nombre Diogo Queixada. Además de esto, también había tenido desencuentros con un tal Jozé García, de origen castellano, que habría atravesado también la frontera. Martim Afonso de Melo indicó que daría orden para que Luis Queixada fuese trasladado a Lisboa, y aconsejó al monarca que debería ordenar a este individuo y todos los que siguieran el mismo camino, embarcarse para las conquistas ultramarinas. No era conveniente que se permitiera a estos hombres permanecer en Portugal, dada la facilidad que tenían para volver a Castilla y el riesgo que se corría de que se convirtieran en los mejores espías que el enemigo podía tener. Era fundamental, insistió, no perder de vista a los extranjeros por la facilidad que tenían para pasar de uno a otro reino por la frontera alentejana:

\footnotetext{
"Este e os mais que se vierem desta sorte se embarquem para as Conquistas, porque o mais de ficarem no Reyno nam convêm pela facilidade com que se tornam a passar pera Castella, sendo as melhores Espias que o Inimigo pode ter neste Reyno, e o mesmo se deve entender com os Estrangeiros que se passam de Castella, pera nós porque tornam a fazer, pera os Castelhanos tanto que em Lisboa lhe dão passaporte" ${ }^{" 56}$.
}

\subsection{Control y aprehensión de la correspondencia}

El 15 de junio de 1646, Joane Mendes de Vasconcelos informó de que a través de correspondencia aprehendida había tenido noticia de que el enemigo castellano contaba con tropas preparadas en Badajoz, a lo que se sumaban diecisiete en Talaveiruela y en Lobón. Advirtió

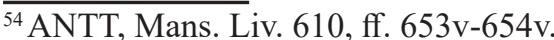

${ }^{55}$ ANTT, Mans. Liv. 610, ff. 210v-211.

${ }^{56}$ ANTT, Mans. Liv. 610, ff. 248v-249v.
} 
que esta sería una gran amenaza para el poderío portugués porque llegaba en un momento en el que casi toda la provincia alentejana estaba pidiendo a gritos más caballería, por razones de seguridad de la población y custodia de su ganado. La verdad es que la caballería portuguesa que se distribuyó por la frontera del Alentejo se encontraba debilitada en todos los lugares. En estas condiciones la capacidad de resistencia al enemigo con eficacia se vio mermada, quedando los principales asientos expuestos a estragos drásticos: "emtrando o Inimigo com poder não hé possivel rezistir-lhe, nem impedir as prezas que intentar, e com isto ficão as Praças principais expostas a mil injurias". Por lo tanto, la única alternativa fue reunir al grueso de la caballería para poder oponerse al enemigo en las zonas más estratégicas y vulnerables, o si no, ensañarse con las entradas que hicieran en otras zonas menos importantes, obligando a sus moradores a retirar el ganado para que el enemigo no se lo robase o los matase ${ }^{57}$.

Gracias también a correspondencia interceptada, el mismo gobernador tomó conocimiento de una empresa que los castellanos habían llevado a cabo en Elvas. El 4 de septiembre del mismo año, informó de que en la noche anterior el enemigo estuvo a punto de secuestrar el correo portugués: "esta noite nos teve o Inimigo quazi tomado o correo, e como a cartalaria anda cançada com contios comboys nam se pode apertar tanto com ella como convem á seguridade" 58 . También indicó que una tropa castellana robó parte del ganado vacuno de la localidad de Vila Boim. Algunos soldados portugueses les tendieron una emboscada, alcanzándoles cuando ya iban por Terena, donde dieron muerte a tres soldados e hicieron dos prisioneros.

Por la correspondencia aprehendida, el gobernador había conseguido detectar además que el enemigo tenía ciento cuarenta y dos caballos en tres tropas, y que esperaban que llegasen algunas más en poco tiempo. Descubrió también que tenían artillería expuesta, aunque no tenían carruajes para transportarla ${ }^{59}$.

E1 23 de noviembre de 1646, este mismo gobernador informó de que en los alrededores de Olivenza habían interceptado a dos mensajeros, uno de Sevilla y otro de Madrid. Examinaron las cartas que llevaban hasta el más mínimo detalle. Analizadas dos de ellas, las que fueron aprehendidas al mensajero de Sevilla, cuyo remitente era Joam de Santelices, y los destinatarios el conde de Fuensaldaña y el marqués de Lolinquen, se dan cuenta de que los castellanos se estaban organizando cerca del "Xeres". Esta información ya había sido dada por los soldados castellanos que estaban prisioneros en Elvas y las cartas sirvieron para confirmar los hechos.

Junto a estas misivas, también se encontró un papel impreso en el que se decía que los castellanos sabían cómo hacer sus acciones y que las llevarían a cabo a cualquier precio. ¿Podría ser esto entendido como una amenaza? ¿Se habría dejado el mensajero emboscar a propósito, con la intención por parte de los castellanos de demostrar a los portugueses que constituían un peligro bien patente? Sea como sea, Joanne Mendes de Vasconcelos alertó de que sería

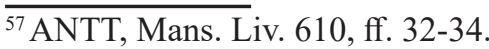

${ }^{58}$ ANTT, Mans. Liv. 610, ff. 98-99.

${ }^{59}$ Ibidem.
} 
bueno que el monarca portugués sacara partido de las advertencias contenidas en los papeles confiscados, con el fin de ser capaces de tener un ejército bien preparado para oponerse al enemigo en la frontera del Alentejo ${ }^{60}$.

El 25 de febrero de 1650, André de Albuquerque transmitió las informaciones que obtuvo por medio de unas cartas en las que se comunica que los castellanos se habían dirigido a Campo Maior para enfrentarse a la caballería de aquella plaza, "para o que se empenhou tanto que chegou a Estacada onde os nossos pelejarão com elle". Por las mismas cartas, se sabe que el enemigo acabó por colocarse en retirada cuando murió su capitán de caballos junto con otros soldados suyos, sin que del lado de los portugueses se hubiesen producido más bajas que la pérdida de un soldado y dos caballos ${ }^{61}$.

Por otras cartas, el Gobernador Martim Afonso de Melo se hizo con otros datos importantes. Así, el 19 de febrero y el 29 de marzo de 1650, dio cuenta de cómo iban las prevenciones y el estado de los asentamientos de Castilla cercanos a la frontera alentejana, especialmente Badajoz. Indica haber solicitado varias veces que se indagase sobre la situación de esta ciudad — “tomar lingoas a Badajos" - para confirmar la información. Por las respuestas que obtuvo, vino a saber que los castellanos habían recibido una gran cantidad de personas extranjeras y muchos caballos, armas y municiones. Así mismo, supieron que trabajaban en el tren de artillería. Para tener más detalles sobre lo que estaba sucediendo, el gobernador había colocado a lo largo de la frontera del Alentejo, con especial énfasis en Olivenza y Castelo de Vide, algunos hombres portugueses de su entera confianza, para que indagaran sobre cuál sería el estado del enemigo y cómo o qué estarían preparando en materia táctica y de defensa: "alguns homens nossos, dos quais espera saber o que o inimigo vay obrando, e juntando terra adentro"62.

Por medio de los datos contenidos en cartas del conde de Cantanhede, sobresaliendo una del 26 de abril de 1650, se tiene conocimiento de lo que se va haciendo en relación a las prevenciones y expedición de socorro en la frontera del Alentejo. Advirtió de que el número de soldados de Portugal era escaso para conseguir responder eficazmente a la guerra entablada en las zonas de la frontera alentejana, auxiliando al mismo tiempo en las conquistas del reino. De esta manera, manifestó la necesidad de traer efectivos de fuera, para no sobrecargar a los que ya estaban en la frontera. Los soldados no podían faltar en absoluto, ni en la guerra, ni como apoyo para la agricultura de los campos, de donde salía el sustento de los que servían en la guerra ${ }^{63}$.

Por carta del Maestro de Campo General del Ejército del Alentejo, João da Costa, fechada el 16 de noviembre del mismo año, tenemos conocimiento de varios avisos de que el enemigo había penetrado en la raya alentejana por los frentes de Castelo de Vide, Alpalhão y Crato, con tropas a caballo y un gran número de soldados asalariados. En esos lugares habían robado parte del ganado vacuno. Había dado orden para que salieran siete tropas al mando del capitán

\footnotetext{
${ }^{60}$ ANTT, Mans. Liv. 610, ff. 157-158v.

${ }^{61}$ ANTT, Cons. Guerra, Mç. 10, doc. 67, sf.

${ }^{62}$ ANTT, Cons. Guerra, Mç. 8, doc. 42, sf.

${ }^{63}$ ANTT, Cons. Guerra, Mç. 10, doc. 118, sf.
} 
Lopo de Sequeira, para que fueran a socorrer a esas localidades y sus aledaños. Estos hombres alcanzaron al enemigo cuando ya iba de retirada con una gran cantidad de ganado. Los soldados portugueses embistieron contra ellos de tal manera que vencieron a su caballería, tomando ciento veinticuatro prisioneros, entre los que se encontraba Fernando de Godoy, algunos tenientes, alféreces y ayudantes de caballería ${ }^{64}$.

El control de la correspondencia también permite que se sepa cómo se trataba a los prisioneros portugueses en Castilla. Por ejemplo, el 14 de junio de 1646, Joane Mendes de Vasconcelos informó al monarca João IV de que lo que había conseguido averiguar sobre el trato que los castellanos daban a los prisioneros portugueses: les mantenían en las prisiones públicas sin darles más alimento que pan ${ }^{65}$.

El 11 de septiembre de 1647, Martim Afonso de Melo había puesto en conocimiento del monarca que el ingeniero Cosmander estaba en prisión. Para intentar tener noticias suyas, se había enviado por correo una carta, pero probablemente la correspondencia habría sido interceptada por los castellanos y urgía cambiar la ruta que seguía el correo:

\footnotetext{
"Succedeo que ontem se tomou o Correo ordinario que vinha de Lisboa, que como tem dia certo sempre vem arriscado, e o tomárão huns pilhantes, isto devia de ser a respeito das perguntas que farám a Cosmander para ver se se ajusta com as cartas, mas foi boa sorte nam tomarem as de V. M. que me tinham vindo por hum correo extraordinario; agora mando mudar o caminho ao correo" $"$.
}

El 18 de septiembre de 1647, advirtió que después de saber de la captura de Cosmander en Castilla, se habían iniciado las negociaciones con Badajoz de la forma acostumbrada, ofreciéndoles dos caballeros castellanos que estaban detenidos en la provincia alentejana, tres oficiales de guerra, siendo uno de ellos el teniente de caballos, y otros dos, un ayudante y un alférez en pago de su rescate.

De acuerdo con órdenes posteriores del monarca portugués, el intercambio de Cosmander tendría que ser sustituido por el del conde de Isiguen: "se nam havia de trocar o Conde de Isinguen se nam fosse por Cosmander" ${ }^{\prime 67}$.

Continuó diciendo que los castellanos querían hacer creer a Cosmander que los portugueses no tenían ningún interés en negociar su rescate; esperaban así los castellanos ganarse el favor del ingeniero, ya que para ellos sería beneficioso tener sus servicios tanto en lo militar como para que se encargara de la proyección de sus fortificaciones; a esto se sumaba la ventaja de que también podrían estar a la par de las debilidades de las fortificaciones lusas en la frontera alentejana: "o que os Castelhanos querem hé desconfiar a Cosmander de que nós nam tratamos

\footnotetext{
${ }^{64}$ ANTT, Cons. Guerra, Mç. 10, doc. 192, sf.

${ }^{65}$ ANTT, Mans. Liv. 610, ff. 70v-71.

${ }^{66}$ ANTT, Mans. Liv. 610, ff. 270-271.

${ }^{67}$ ANTT, Mans. Liv. 610, ff. 278-279v.
} 
de seu troquo, pera com isso cuidarem que lhe será de proveito contra nós". Por lo tanto, Martim Afonso de Melo dio órdenes para que siempre que le escribieran les hablasen de las intenciones de rescatarle. Pero, como Cosmander no podía comunicarse más que con quien le dejaran los castellanos, lo más seguro sería que él no tuviese acceso a ninguna de las cartas de los lusos. A pesar de todo, como los portugueses no estaban dispuestos a realizar ningún intercambio si no era por el conde de Isinguen, lo más probable sería que los castellanos permitieran el retorno de Cosmander al Alentejo ${ }^{68}$.

Dicho esto, el 23 del mismo mes, el Gobernador dio noticia de que hasta entonces los castellanos no habían querido plantearse hablar del intercambio de Cosmander, ni del conde de Isinguen. El enemigo había llegado a advertir que no harían llegar a Cosmander ninguna de las cartas que les fuesen destinadas y que mencionasen su intercambio. Tampoco quisieron recibir la carta enviada por el conde de Isinguen a su mujer, pues esta mencionaba el asunto. Por lo tanto, Martin Afonso de Melo consideraba necesario que fuese la condesa de Isinguen quien escribiera a Cosmander hablándole del tema para que los castellanos no desconfiaran: "pera que possam chegar-lhe a Madrid estas novas, que por aqui está o caminho serrado, e os Castelhanos querem se escreva a Cosmander sem fallar em troquo só pelo desconfiarem mais de que nós nam tratamos delle"69.

El 6 de octubre del mismo año, todavía seguía intentándose el intercambio de Cosmander por el conde de Isinguen o por el conde Fiesco. Este día, Martim Afonso de Melo informó que en las cartas que le fueron interceptadas a un mensajero de Badajoz, podía leerse que el marqués de Molinguem había partido el día cinco de ese mes hacia Madrid, acompañado de Cosmander - "elles haviam de levar comboy athé Talaveyra de La Reina". Los portugueses organizaron una emboscada con cuarenta caballos cerca de Trozilhos, "a cargo de hum Tenente homem de vâlor, e com soldados valentes e praticos no Paiz pera que junto aquella cidade investissem com tudo o que fosse com o Molinguen". Era más conveniente que esta empresa se llevase a cabo durante la noche por la confusión que permitiría causar: "permitta Deos dar-nos algum sucesso bom sendo tambem o intento de poder libertar a Cosmander, e pelo menos que veja elle que fazemos todo o possivel por isso"70.

Señalar que, a pesar de todos los intentos llevados a cabo para recuperar a este ingeniero militar, Cosmander se alistó en las filas del enemigo en 1648.

Para terminar, dejo constancia de una carta fechada el 5 de febrero de 1648, que llegó a manos de Martim Afonso de Melo, a través de la requisa de un correo enemigo, en la que se deja ver de forma notoria que los castellanos buscaban todas las vías posibles para arruinar los reinos del monarca portugués, cometiendo incluso algunos excesos. Según él, los portugueses tenían que aprovechar la ventaja que les daba esta información para ganar tiempo: "parece

\footnotetext{
$\overline{{ }^{68} \text { Ibídem, f. } 278 \mathrm{v}-279 .}$

${ }^{69}$ ANTT, Mans. Liv. 610, ff. 282-283.

${ }^{70}$ ANTT, Mans. Liv. 610, f. 295v-296.
} 
será mayor culpa nossa se não tratamos de aproveitar o tempo, e a occazião que de prezente se offerece por ser a melhor e a mais a preposito que podiamos dezejar". En la misma carta, advirtió que el Gobernador de Armas de Badajoz solo actuaba por placer y comodidad, sin que le preocupara lo más mínimo su caballería, que sería la que haría mayor daño a los portugueses. Además, no tenía infantería asalariada, y ni un solo soldado preparado. Por lo tanto, cuando se enterasen de que los portugueses se acercaban, intentarían reforzarse con soldados efectivos de fuera para que les ayudasen a defenderse más rápidamente, pero acabarían por ser derrotados de todos modos porque no contaban con infraestructuras para almacenar los abastecimientos de guerra. Advirtió que los intereses que los portugueses podrían tener de esta facción serían muy grandes, tanto en los servicios públicos de los vasallos del monarca portugués, como en la hacienda real. Así, a las plazas más grandes, como Campo Maior, Olivenza y Elvas, les bastaría una guarnición pequeña para considerarse muy bien preparadas para recibir al enemigo. En su opinión:

\footnotetext{
"O credito e reputação das Armas de V. M. nam tem comparação no que vem a ganhar com rezolução deixando de dizer muitas mais conveniencias me parece a mayor de todas o por a guerra que temos na terra do Inimigo, e tão afastada de nós a Sua Praça de Armas, como hé Merida que sam nove ou dez legoas de Badajos, e pode-se ter por sem duvida que se tivermos ganhado aquella Praça que todos os lugares pequenos da Extremadura ham de contribuir a V. M., se os quizerem os Castelhanos habitar, quando nam fará V. M. delles o que melhor parecer, porque doutra maneyra se nam podem sustentar" ${ }^{271}$.
}

\section{Conclusión}

Del análisis de las cartas mencionadas, es posible dilucidar la importancia que tenía la correspondencia entre los gobernadores y el Ejército de la frontera del Alentejo para el monarca en tiempo de guerra. A decir verdad, suponía una herramienta de control para el rey y le permitía ser consciente de lo que estaba ocurriendo en la raya alentejana, donde el enemigo tenía más facilidad para penetrar por ser una extensión plana. Por ese motivo, necesitaba una vigilancia reforzada y un control más acentuado. A pesar de los cuidados tomados, era común el trasiego de soldados huyendo entre uno y otro reino. La aprehensión de cartas del enemigo permitió desvelar algunos nombres de los transgresores. Lo vemos en casos como el del soldado Francisco de Castilho, que huyó a Portugal en 1646, tras haber asesinado a un hombre; o el de

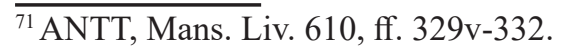


Luís Queixada, quien se instaló en Elvas tras sus desavenencias con un sirviente de un pariente suyo, el capitán de caballos Diogo Queixada y con Jozé García, que también había cruzado la frontera por aquellos días.

En sentido inverso, el cruce desde Portugal a Castilla, dase a conocer el caso de João Soares Vivas, Gonçalo de Barros, João de Barros y tres sirvientes suyos. Además de ellos, también huyeron hacia Castilla soldados de las compañías del comisario general Alexandre Vanhaterm y del capitán Gerardo Vanigen.

En un periodo de espías de los dos lados de la frontera, las cartas se antojaron una herramienta preciosa para controlar la posición y el estado de preparación del enemigo, permitiendo también el cálculo de lo que se podía avanzar en las obras de fortificación para defender las zonas más vulnerables y fáciles de penetrar dada su topografía.

Como hemos podido constatar, las obras en las fortificaciones tenían muchos problemas para avanzar debido a la falta de dinero. En la carta del 21 de enero de 1648, queda patente que el motivo por el que no se podía completar la fortificación de Campo Maior era puramente monetario. Otro ejemplo lo tenemos en la carta del 2 de diciembre de 1646, en la que se establece que Ouguela está expuesta debido a la debilidad de su fortificación. Para terminar, en la carta que data del día 5 del mismo mes, se hace referencia a la importancia de la plaza de Juromenha, en la que, a pesar de haberse proyectado tres plantas de fortificación diferentes, las obras no avanzaban por falta de dinero.

A partir de las transcripciones de las cartas presentadas también es posible ver la voluntad que los vecinos rayanos manifestaban por ver las poblaciones del Alentejo bien defendidas y fortificadas para su propia seguridad. Buena prueba de ello es la carta de junio de 1646, en la que los párrocos de Évora se muestran dispuestos a invertir dinero en la construcción de la fortificación para impedir la entrada del ejército enemigo. Otra carta, esta del 16 de febrero de 1650 da cuenta de que las gentes de Elvas decidieron contribuir voluntariamente con su dinero, mediante impuestos, para el avance de las obras en la fortificación.

Entre los motivos que llevaron a la interrupción de las obras se encuentra también el hecho de que los ingenieros militares Cosmander, en 1648, y Nicolau de Langres, en 1662, pasaron a servir al enemigo castellano, lo que provocó un cambio de planes en la construcción de las fortificaciones, ya que las obras pasaron a manos de otros ingenieros militares con menos experiencia.

La documentación tratada en los archivos fue muy importante para la elaboración de este artículo; fruto de su lectura atenta son los datos que se traen a la luz y que, sin duda, enriquecen el análisis de la historia de la frontera entre Portugal y Castilla durante la guerra de Restauración. 